\title{
Effect of Vitamin C on Blood Loss during FESS in Patients with chronic rhinosinusitis
}

\author{
Vahid Zand ${ }^{1}$, Azade Dehghanmarvast ${ }^{1}$, Sedighe Vaziribozorg ${ }^{1 *}$
}

1 Department of Otolaryngology- Head and Neck Surgery, Otorhinolaryngology Research Center, Shahid Sadoughi University of

Medical Sciences, Yazd, Iran

*Corresponding Author: Dr. Sedighe Vaziribozorg, Department of Otolaryngology- Head and Neck Surgery, Otorhinolaryngology Research Center, Shahid Sadoughi University of Medical Sciences, Yazd, Iran.

Email: s.vaziribozorg1408@gmail.com; Tel: 00983538224000

Received: September 10, 2020; Accepted: January 22, 2021

\begin{abstract}
Introduction: In this study we assessed the effect of vitamin C on blood loss during endoscopic sinus surgery. Materials and methods: In this double-blind clinical trial study 91 patients suffered from chronic rhinosinusitis with nasal polyposis undergoing endoscopic sinus surgery involved. Patients in the case group (group A) received $3 \mathrm{~g}$ of vitamin $\mathrm{C}$ in $500 \mathrm{cc}$ of normal saline intravenously over a half hour at the beginning of the surgery. Patients in the control group (group B) received the same volume of normal saline under similar condition. Ultimately, intraoperative blood loss, surgery duration, and the quality of surgical field were assessed. Results: The mean of blood loss was $211.47 \mathrm{cc}$ in group A and it was 281.52 $c c$ in group $B$, indicating a significant difference between two groups ( $p$ value $=0.03$ ). The quality of surgical field, according to Boezaart scale, was also significantly better in group A ( $p$ value= 0.016). However, no significant difference was observed between groups in terms of surgeon's satisfaction score. Conclusion: According to the results, we can conclude that preoperative administration of vitamin $\mathrm{C}$ could improve surgical field and reduce blood loss during endoscopic sinus surgery.
\end{abstract}

Keywords: Vitamin C, Endoscopic Sinus Surgery, Chronic Rhinosinusitis.

\section{INTRODUCTION}

Rhinosinusitis is defined as a group of diseases associated with inflammation of the nasal mucosa and paranasal sinuses ${ }^{[1]}$. It is called chronic rhinosinusitis when the inflammation lasts for more than 12 consecutive weeks ${ }^{[2]}$. Chronic rhinosinusitis is a relative indication for sinus surgery. Surgery is indicated for patients when medical treatment fails to improve the disease symptoms and endoscopic surgery is a common and selective treatment in this condition ${ }^{[3]}$. Due to the vascular nature and vascularity of the nasal and sinus mucosa, one of the most common considerations during endoscopic sinus surgery is bleeding ${ }^{[4]}$. Bleeding increases the risk of damage to adjacent vital organs, prolongs the surgery by diminishing the view of the surgeon, decreases the surgery success rate, and even sometimes stops surgery before achieving the desired outcome [5]. Several techniques such as diathermy bipolar, topical vasoconstriction, local injection of epinephrine, and induced hypotension have been proposed to enhance the surgical field in endoscopic sinus surgery. Nevertheless, these techniques can not permanently offer an ideal field for the surgeons and bleeding during endoscopic sinus surgery continues to be a challenge for surgeons and anesthesiologists [6,7]. Vitamin C, known as ascorbic acid, has a proven role in repair of tissue as well as reduction of different pains. Due to connective tissue disorder in the vessel wall, the tendency to bleeding increases following vitamin $\mathrm{C}$ deficiency in the body. Also ascorbic acid plays an important role in the proper functioning of the platelet (antioxidant and free oxygen level reducer) ${ }^{[8]}$. In various studies, besides mentioning the beneficial effects of vitamin $C$ in preventing and controlling bleeding, no side effects were reported following high intake of vitamin $C[9,10]$. However, in some other studies the results showed that in patients with kidney functional impairment, glucose 6-phosphate dehydrogenase deficiency and paroxysmal nocturnal hemoglobinuria, excessive intake of ascorbic acid could develop hemolysis ${ }^{[11,12]}$. This study investigated the effect of intravenous administration of vitamin $\mathrm{C}$ on bleeding during endoscopic sinus surgery.

\section{METHODS AND MATERIALS}

After approval by the local Ethics Committee and obtaining written informed consent, in this double-blind clinical trial study 91 patients suffering from rhinosinusitis with nasal polyposis 
(CRSwP) undergoing endoscopic sinus surgery were involved. Patients with history of prior nasal and sinus surgery, high blood pressure (systolic blood pressure> 14 and diastolic blood pressure $>9$ ), underlying diseases (antiphospholipid syndrome, cancer, pregnancy, and coagulation disorders) and history of taking medications which is associated with the risk of thrombosis or bleeding, were excluded. The patients underwent concurrent endoscopic sinus surgery and septoplasty were excluded from the study too. Patients were randomly assigned to two groups using a random number table. Patients in the case group (group $A=45$ ) received $3 \mathrm{~g}$ of vitamin $C$ in $500 \mathrm{cc}$ normal saline intravenously over a half hour at the beginning of the surgery after induction of anesthesia (The anesthesia protocol was the same for all the patients). Patients in the placebo group (group $B=46$ ) received the same volume of normal saline. All the patients underwent endoscopic sinus surgery by the same surgeon and the same anesthesiologist. The surgeon was blinded to which medication was used for each patient. Intraoperative blood loss from the site of surgery was collected for each patient in a separate suction canister. Finally, blood-loss volume was calculated by subtracting the volume of irrigation fluid from the total volume collected in the suction container. We did not use nasal packing or local infiltration for any of the patients. The duration of the operation was recorded for each patient. The quality of the surgical field was determined according to Boezaart Scale (ranged from 0 to 5) (Table.1) ${ }^{[13]}$. The surgeon's satisfaction with bleeding control and the surgical field was also recorded based on 5-point Likert Scale (very bad, bad, moderate, good, and excellent). In addition, the degree of sinus involvement was assessed based on Lund-Mackay Score. Also, patients were evaluated for any side effects (diarrhea, dizziness, faintness, flushing or redness of skin, headache, increase in urination, stomach cramps). Data were analyzed using SPSS (version 20) and P. value $<0.05$ was considered significant.

Table 1: Boezaart Scale

\begin{tabular}{|c|c|}
\hline Grade & Assessment \\
\hline 0 & No bleeding (cadaveric conditions) \\
\hline 1 & Slight bleeding-no suctioning required \\
\hline 2 & Slight bleeding-occasional suctioning required \\
\hline 3 & $\begin{array}{l}\text { Slight bleeding-frequent suctioning required. } \\
\text { Bleeding threatens surgical field a few } \\
\text { seconds after suction is removed }\end{array}$ \\
\hline 4 & $\begin{array}{l}\text { Moderate bleeding-frequent suctioning } \\
\text { required and bleeding threatens surgical field } \\
\text { directly after suction is removed }\end{array}$ \\
\hline 5 & $\begin{array}{l}\text { Severe bleeding-constant suctioning required; } \\
\text { bleeding appears faster than can be removed } \\
\text { by suction; surgical field severely threatened } \\
\text { and surgery usually not possible }\end{array}$ \\
\hline
\end{tabular}

\section{RESULTS}

In this double-blind clinical trial study 91 patients suffering from rhinosinusitis with nasal polyposis (CRSwP) undergoing endoscopic sinus surgery were involved. The mean age of patients in group $A$ was $43.13 \pm 11.17$ years and in the placebo group was $40.33 \pm 13.38$ years. There were 19 males $(42.2 \%)$ and 26 females (57.8\%) in group A, and there were 23 males $(50 \%)$ and 23 females $(50 \%)$ in group B. There were no significant differences between two groups regarding age and sex $(p>0.05)$. The mean of blood loss was $211.47 \mathrm{cc}$ in group $A$ and $281.52 \mathrm{cc}$ in group $\mathrm{B}$, indicating a significant difference between two groups ( $p$ value $=0.03$ ). The mean of surgical duration was 122.29 minutes in group $A$ and 120.65 minutes in group $B$, which did not lead to statistically significant difference between two groups $(p=0.85)$. Considering the quality of surgical field, according to Boezaart scale, quality of surgical field was significantly better in group $A$ ( $p$ value $=0.016)$ (Table. 2 ). In both groups, in most cases, the surgeon's satisfaction was good but the difference between two groups was not significant in this regard $(p=0.27)$ (Table. 3$)$. The mean score of sinus involvement, based on Lund-Mackay Score, was 19.04 in group $A$ and 16.37 in group $B$, which revealed a significant difference $(p=0.02)$. In other words, the degree of sinus involvement in the vitamin C group (group A) was significantly higher than that in the control group (group B). No side effects (Vitamin C sideeffects) (diarrhea, dizziness, faintness, flushing or redness of skin, headache, increase in urination, stomach cramps) and post-surgery bleeding was reported.

Table 2: Quality of surgical field between two groups.

\begin{tabular}{|c|c|c|c|c|c|c|c|c|}
\hline \multirow{2}{*}{$\begin{array}{l}\mathrm{P}- \\
\text { value }\end{array}$} & \multirow[t]{2}{*}{ total } & \multicolumn{5}{|c|}{ Quality of surgical field } & \multirow{2}{*}{\multicolumn{2}{|c|}{ group }} \\
\hline & & 5 & 4 & 3 & 2 & 1 & & \\
\hline \multirow[t]{6}{*}{0.016} & 45 & 0 & 12 & 20 & 11 & 2 & number & \multirow[t]{2}{*}{ Vit c } \\
\hline & $100 \%$ & $0 \%$ & $26.7 \%$ & $44.4 \%$ & $24.4 \%$ & $4.4 \%$ & percent & \\
\hline & 46 & 10 & 6 & 18 & 10 & 2 & number & \multirow[t]{2}{*}{ placebo } \\
\hline & $100 \%$ & $21.7 \%$ & $13 \%$ & $39.1 \%$ & $21.7 \%$ & $4.3 \%$ & percent & \\
\hline & 91 & 10 & 18 & 38 & 21 & 4 & number & \multirow[t]{2}{*}{ total } \\
\hline & $100 \%$ & $11 \%$ & $19.8 \%$ & $41.8 \%$ & $23.1 \%$ & $4.4 \%$ & percent & \\
\hline
\end{tabular}

Table.3: surgeon's satisfaction between two groups.

\begin{tabular}{|l|l|l|l|l|l|l|l|}
\hline $\begin{array}{l}\text { P- } \\
\text { value }\end{array}$ & total & \multicolumn{2}{|l|}{ surgeon's satisfaction } & \multicolumn{2}{l|}{ group } \\
\cline { 3 - 7 } & & Excellent & Good & Moderate & Bad & \\
\hline 0.27 & 45 & 6 & 25 & 14 & 0 & number & Vit c \\
\cline { 2 - 7 } & $100 \%$ & $13.3 \%$ & $55.6 \%$ & $31.1 \%$ & $0 \%$ & percent & \\
\cline { 2 - 6 } & 46 & 10 & 19 & 15 & 2 & number & placebo \\
\cline { 2 - 6 } & $100 \%$ & $21.7 \%$ & $41.3 \%$ & $32.6 \%$ & $4.3 \%$ & percent & \\
\cline { 2 - 6 } & 91 & 16 & 44 & 29 & 2 & number & total \\
\cline { 2 - 6 } & $100 \%$ & $17.6 \%$ & $48.4 \%$ & $31.9 \%$ & $2.2 \%$ & percent & \\
\hline
\end{tabular}

\section{DISCUSSION}

Surgery is indicated in patients suffering from chronic rhinosinusitis with polyposis when medical treatments fail to improve disease symptoms and endoscopic surgery is a common and selective method in this situation [3]. Due to vascular nature and high viscosity of nasal and sinuses mucosa, one of the most common considerations during endoscopic sinus surgery is bleeding [4]. The present double blind randomized clinical trial study aimed to investigate the effect of vitamin $\mathrm{C}$ on blood loss during endoscopic sinus surgery. The findings of this study showed that intravenous administration of $3 \mathrm{~g}$ of vitamin $\mathrm{C}$ preoperatively significantly reduced the amount of blood loss in case group $(n=45)$ compared to control group. Based on our findings, the quality of surgical field was also significantly better in case group according to Boezaart scale. To best of our knowledge, no study has investigated the effect of vitamin $\mathrm{C}$ on blood loss during endoscopic sinus surgery yet. Byshevskii ASH et al., in a systematic review study showed that ascorbic acid played an important role in enhancing the 
homeostasis system [14]. Blee et al., found that vitamin C deficiency in patients undergoing surgery, even with normal coagulation parameters, could lead to postoperative bleeding, chronic blood loss, or need for blood transfusion. They also revealed that administration of 250 to $1000 \mathrm{mg}$ of oral vitamin C could prevent long-term admissions and subsequent bleeding. Furthermore, they reported that vitamin $C$ deficiency could be one of the non-specific causes of bleeding in patients undergoing surgery ${ }^{[15]}$. In a study conducted by Pourmatroud et al. in 2012 on 102 patients (case group=52) undergoing myomectomy, a significant decrease in bleeding ( $p$. value $=0.001$ ), duration of surgery, and length of hospital stay was reported in patients receiving vitamin $\mathrm{C}(2 \mathrm{~g})^{[16]}$, so findings were in line with ours ( case group=45). Ayatollahi et al., (2016) investigated the effect of intravenous vitamin $C$ on postoperative pain in patients undergoing uvulopalatopharyngoplasty with tonsillectomy. In their study, case group $(n=20)$ received the infusion of $3 \mathrm{~g}$ vitamin $\mathrm{C}$ in $500 \mathrm{~mL}$ of Ringer and placebo group received $6 \mathrm{~mL}$ normal saline in $500 \mathrm{~mL}$ of Ringer. According to their results there was no significant differences in bleeding between two groups $(P$-value $=0.49)$ so their findings were in contrast with ours ${ }^{[17]}$. Kim et al., (2016) investigated the effect of intravenous administration of ascorbic acid on bleeding during laparoscopic myomectomy. In their study, 30 minutes before anesthesia, $2 \mathrm{~g}$ of ascorbic acid was prescribed for the case group $(n=24)$ and the same volume of placebo was administrated to the control group. The average volume of bleeding was not significantly different between two groups [18], so their findings were in contrast with ours. This difference between findings of our study compare with Ayatollahi and Kim studies is probably due to small sample size in their studies.

\section{CONCLUSION}

According to our results, since administration of vitamin $\mathrm{C}(3 \mathrm{~g})$ at the beginning of surgery significantly reduced the amount of bleeding in case group compared to control group and also since the quality of surgical field, based on Boezaart scale, was significantly better in vitamin $\mathrm{C}$ group, we can conclude that preoperative administration of vitamin $\mathrm{C}$ is suggested to improve surgical field and reduce blood loss during endoscopic sinus surgery. However, future studies are suggested using larger sample size, comparing vitamin $\mathrm{C}$ administration with other interventions, and assessing different doses of vitamin $\mathrm{C}$.

\section{"Compliance with Ethical Standards"}

\section{${ }^{*}$ Authors have no conflicts of interest.}

* Study protocol was in accordance with the latest Declaration of Helsinki for medical research involving human subjects and was approved by local ethics committee. *This article does not contain any studies with animals
performed by any of the authors.

* Informed consent was obtained from all participants of the study.

\section{REFERENCES}

1. Benninger MS, Ferguson BJ, Hadley JA, Hamilos DL, Jacobs M, Kennedy DW, et al. Adult chronic rhinosinusitis: definitions, diagnosis, epidemiology, and pathophysiology. Otolaryngologyhead and neck surger: official journal of American Academy of Otolaryngology-Head and Neck Surgery. 2003; 129(3 Suppl):S132.
2. Meltzer EO, Hamilos DL, Hadley JA, Lanza DC, Marple BF, Nicklas RA, et al. Rhinosinusitis: establishing definitions for clinical research and patient care. Journal of allergy and clinical immunology. 2004; 114(6):155-212.

3. Flint PW, Haughey BH, Niparko JK, Richardson MA, Lund VJ, Robbins KT, et al. Cummings Otolaryngology-Head and Neck Surgery E-Book: Head and Neck Surgery, 3-Volume Set: Elsevier Health Sciences; 2010.

4. Stammberger $\mathrm{H}$. Functional endoscopic nasal and paranasal sinus surgery. The Messerklinger technique Toronto-Philadelphia: BC Decker. 1991.

5. Ragab SM, Hassanin MZ. Optimizing the surgical field in pediatric functional endoscopic sinus surgery: a new evidence-based approach. Otolaryngology--head and neck surgery. 2010; 142(1):48-54.

6. Riegle EV, Gunter JB, Lusk RP, Muntz HR, Weiss KL. Comparison of vasoconstrictors for functional endoscopic sinus surgery in children. The Laryngoscope. 1992; 102(7):820-3.

7. Wormald P-J, Athanasiadis T, Rees G, Robinson S. An evaluation of effect of pterygopalatine fossa injection with local anesthetic and adrenalin in the control of nasal bleeding during endoscopic sinus surgery. American journal of rhinology. 2005; 19(3):288-92.

8. Savini I, Catani MV, Arnone R, Rossi A, Frega G, Del Principe D, et al. Translational control of the ascorbic acid transporter SVCT2 in human platelets. Free Radical Biology and Medicine. 2007; 42(5):608-16.

9. Wong K, Thomson C, Bailey R, McDiarmid S, Gardner J. Acute oxalate nephropathy after a massive intravenous dose of vitamin C. Australian and New Zealand journal of medicine. 1994; 24(4):410-1.

10. De La Vega LP, Lieske JC, Milliner D, Gonyea J, Kelly DG. Urinary oxalate excretion increases in home parenteral nutrition patients on a higher intravenous ascorbic acid dose. Journal of Parenteral and Enteral Nutrition. 2004; 28(6):435-8.

11. Campbell JG, Steinberg MH, Bower JD. Ascorbic acid-induced hemolysis in G-6-PD deficiency. Annals of internal medicine. 1975; 82(6):810.

12. Imamoto N, Kawaguchi T, Horikawa K, Nagakura S, Hidaka M, Kagimoto $\mathrm{T}$, et al. Haemolysis induced by ascorbic acid in paroxysmal nocturnal haemoglobinuria. The Lancet. 1994; 343(8893):357.

13. Athanasiadis T, Beule AG, Wormald PJ. Effects of topical antifibrinolytics in endoscopic sinus surgery: a pilot randomized controlled trial. American journal of rhinology. 2007; 21(6):737-42.

14. Byshevskii A, Mataev S, Rudzevich A, Shpovalova E. Hemostasis and maintenange of the organism vitamin C. Voprosy pitaniia. 2008; 77(3):21-8.

15. Blee TH, Cogbill TH, Lambert PJ. Hemorrhage associated with vitamin C deficiency in surgical patients. Surgery. 2002; 131(4):408-12.

16. Pourmatroud E, Hormozi L, Hemadi M, Golshahi R. Intravenous ascorbic acid (vitamin C) administration in myomectomy: a prospective, randomized, clinical trial. Archives of gynecology and obstetrics. 2012; 285(1):111-5.

17. Ayatollahi V, Dehghanpour Farashah S, Behdad S, Vaziribozorg $S$, Rabbani Anari M. Effect of intravenous vitamin $C$ on postoperative pain in uvulopalatopharyngoplasty with tonsillectomy. Clinical Otolaryngology. 2017; 42(1):139-43.

18. Lee B, Kim K, Cho HY, Yang EJ, Suh DH, No JH, et al. Effect of intravenous ascorbic acid infusion on blood loss during laparoscopic myomectomy: a randomized, double-blind, placebocontrolled trial. European Journal of Obstetrics \& Gynecology and Reproductive Biology. 2016; 199:187-91. 